\title{
Editorial: Type I Chaperonins: Mechanism and Beyond
}

\author{
Adina Breiman $^{1 *}$ and Abdussalam Azem ${ }^{2 *}$ \\ 1 School of Plant Sciences and Food Security, Tel Aviv, Israel, ${ }^{2}$ School of Neurobiology, Biochemistry and Biophysics, \\ George S. Wise Faculty of Life Sciences, Tel Aviv University, Tel Aviv, Israel
}

Keywords: chaperonin 60, chaperonins, GroEL, HSP10, GroES

\section{Editorial on the Research Topic}

\section{Type I Chaperonins: Mechanism and Beyond}

\section{OPEN ACCESS}

Edited by:

Anat Ben-Zvi,

Ben-Gurion University of the Negev,

Israel

Reviewed by:

Paolo De Los Rios,

École Polytechnique Fédérale de

Lausanne, Switzerland

Hays S. Rye,

Texas A\&M University, United States

*Correspondence:

Adina Breiman

adinab@tauex.tau.ac.il

Abdussalam Azem

azema@tauex.tau.ac.il

Specialty section:

This article was submitted to Protein Folding, Misfolding and

Degradation,

a section of the journal

Frontiers in Molecular Biosciences

Received: 08 June 2018

Accepted: 09 July 2018

Published: 31 July 2018

Citation:

Breiman A and Azem A (2018)

Editorial: Type I Chaperonins:

Mechanism and Beyond.

Front. Mol. Biosci. 5:72.

doi: 10.3389/fmolb.2018.00072
Chaperone proteins control almost all aspects of proteostasis, such as protein synthesis, translocation, folding, and degradation. As such, chaperones accompany every protein from its birth until its death. Chaperonins constitute a highly conserved subgroup of molecular chaperones that is divided into two groups, Type I and Type II. For Type I chaperonins, the protein folding function is mediated by the Hsp60 (also known as Cpn60) chaperonin, which serves as a folding chamber for denatured protein, assisted by its $10 \mathrm{kDa}$ co-chaperonin, Hsp10 (or Cpn10). For Type II chaperonins, the protein folding function is handleed by a single Hsp60 protein, CCT/TRiC (Horwich et al., 2006, p. 5464; Dekker et al., 2011; Skjaerven et al., 2015). Several important milestones are worth mentioning that led to our current understanding of the molecular of function of Type I chaperonins. The latter were discovered in the 1970s as bacterial host proteins that are essential for the assembly of phage particles (Georgopoulos et al., 1973). During the same period, the heat shock response of some chaperones was discovered (Ritossa, 1962). Conditions known to compromise protein folding. Additional in vivo studies showed that chaperonins are key players in the assembly process of RuBisCO in plants and that they are important for the folding of newly translocated proteins into the mitochondrial matrix as well (Hemmingsen et al., 1988; Roy et al., 1988; Cheng et al., 1989; Goloubinoff et al., 1989).

These discoveries led to general recognition of Type I chaperonins as important protein nano machines that play a key role in cellular protein folding and assembly. In vitro reconstitution of their protein folding activity using denatured dimeric $\mathrm{RuBisCO}$ as a model system opened the door to a new field of research, which focused on in vitro mechanistic aspects of chaperonin function (Goloubinoff et al., 1989). The friendly nature of the Escherichia coli chaperonins, in particular the profound stability of the protein oligomers, enabled their extensive investigation, which established them as the prototype chaperonin model system. Notably, the preponderance of research in the field focused on mechanistic aspects of this bacterial chaperone system.

With time, investigation of chaperonins from chloroplasts, mitochondria, and numerous additional bacterial strains, revealed a wide range of divergence from the $E$. coli paradigm. The vast diversity among chaperonins and atypical systems such as those as discovered in bacteriophages, is reviewed in two manuscripts (Ansari and Mande; Bhatt et al.).

In the case of chloroplast chaperonins, the most striking observation was that these chaperonins assemble into hetero-oligomeric tetradecamers that are composed of several homologous subunits, in contrast to the homo oligomeric nature of bacterial chaperonins. The chloroplast chaperonins are the subject of three manuscripts in this research topic (Zhao and Liu; Vitlin Gruber and Feiz; Vitlin Gruber et al.). Two of them highlight the sophisticated RuBisCO assembly pathway, with new assembly factors identified in recent years, and the complexity of the chloroplast chaperonin system. Recent discoveries in the field represent an important step toward possibly engineering more efficient RuBisCO thereby potentially increasing crop yield. 
With regard to mitochondrial chaperonins, these were also found to exhibit unique structural properties and retain unexpected extra-organelle moonlighting functions. As such, they were found to function in a variety of processes, including signal transduction events that may regulate immunity and inflammation (Athanasas-Platsis et al., 2004; Grundtman et al., 2011; Jia et al., 2011; Juwono and Martinus, 2016). Mitochondrial Hsp60 was suggested to adopt variations in its oligomeric state, in a nucleotide and concentration-dependent manner that may affect its function. Vilasi et al. review the oligomeric variability of mitochondrial Hsp60 and its link to functions that are not related to protein folding (cytosolic and extracellular) (Vilasi et al.). Due to their extra mitochondrial functions, in particular in tumors, Hsp60 has been considered to be a potential target for anticancer drugs. Meng et al. provide an updated review of available compounds that inhibit or affect the function of Hsp60 chaperonins (Meng et al.), with an eye toward using them as anticancer drugs.

In the biotechnology arena, O'Neil et al. developed a highly sophisticated system that utilizes immobilized GroEL on sensors for the detection of aggregated proteins among the various species in solution (O’Neil et al.).

For almost three decades, research on the bacterial GroEL/GroES chaperonin molecular mechanism of function has been central in the field of chaperone proteins (Thirumalai and Lorimer, 2001; Horwich et al., 2006; Gruber and Horovitz, 2016; Hayer-Hartl et al., 2016). The identity of active forms during the reaction cycle, whether the symmetrical $(\mathrm{GroEL})_{14}\left((\mathrm{GroES})_{7}\right)_{2}$ (also named footballs) or the asymmetrical (GroEL) ${ }_{14}(\mathrm{GroES})_{7}$ complexes (bullets), the role of chaperonins in the cycle (e.g., passive or active) and the role of ATP (Goloubinoff et al., 2018) all are discussed in several of the contributions, particularly in Weiss et al. The molecular function of the mitochondrial

\section{REFERENCES}

Athanasas-Platsis, S., Somodevilla-Torres, M. J., Morton, H., and Cavanagh, A. C. (2004). Investigation of the immunocompetent cells that bind early pregnancy factor and preliminary studies of the early pregnancy factor target molecule. Immunol. Cell Biol. 82, 361-369. doi: 10.1111/j.0818-9641.2004. 01260.x

Cheng, M. Y., Hartl, F. U., Martin, J., Pollock, R. A., Kalousek, F., Neupert, W., et al. (1989). Mitochondrial heat-shock protein hsp60 is essential for assembly of proteins imported into yeast mitochondria. Nature 337, 620-625. doi: $10.1038 / 337620 \mathrm{a} 0$

Dekker, C., Willison, K. R., and Taylor, W. R. (2011). On the evolutionary origin of the chaperonins. Proteins 79, 1172-1192. doi: 10.1002/prot.22952

Farr, G. W., Fenton, W. A., Chaudhuri, T. K., Clare, D. K., Saibil, H. R., and Horwich, A. L. (2003). Folding with and without encapsulation by cis- and trans-only GroEL-GroES complexes. EMBO J. 22, 3220-3230. doi: $10.1093 /$ emboj/cdg313

Georgopoulos, C. P., Hendrix, R. W., Casjens, S. R., and Kaiser, A. D. (1973). Host participation in bacteriophage lambda head assembly. J. Mol. Biol. 76, 45-60. doi: 10.1016/0022-2836(73)90080-6

Goloubinoff, P., Christeller, J. T., Gatenby, A. A., and Lorimer, G. H. (1989). Reconstitution of active dimeric ribulose bisphosphate carboxylase from an unfoleded state depends on two chaperonin proteins and Mg-ATP. Nature 342, 884-889. doi: 10.1038/342884a0
Hsp60/Hsp10 chaperonin system receives special attention in this context. Initially, it was suggested that Hsp60 operates as a single ring (Nielsen and Cowan, 1998; Nielsen et al., 1999), rather than a double ring as suggested for GroEL. In Weiss et al, based on results obtained in several studies, an alternative model was endorsed for the Hsp60 reaction cycle (Weiss et al.). This model proposes that mitochondrial Hsp60 alternates between single ring and double ring structures. This "equatorial split" is probably essential for the proper function of the mitochondrial system. Notably, such equatorial split mechanism was originally suggested for Thermus Thermophilus (Ishii et al., 1995), proposed also for GroEL (Taguchi, 2015) and recently received additional experimental support (Yan et al., 2018). Notably, preventing the equatorial split of the rings, by either formation of S-S bonds (Yan et al., 2018) or covalent fusion, still allows for significant protein folding activity by GroEL (Farr et al., 2003). Thus, the functional significance of the ring split for GroEL still requires further investigation.

\section{AUTHOR CONTRIBUTIONS}

All authors listed have made a substantial, direct and intellectual contribution to the work, and approved it for publication.

\section{FUNDING}

AA is supported by United States-Israel Binational Science Foundation (no. 2015214) and the Israel Science Foundation (No. 1507/13).

\section{ACKNOWLEDGMENTS}

We thank Dr. Celeste Weiss for critically reading this manuscript.

Goloubinoff, P., Sassi, A. S., Fauvet, B., Barducci, A., and De Los Rios, P. (2018). Chaperones convert the energy from ATP into the nonequilibrium stabilization of native proteins. Nat. Chem. Biol. 14, 388-395. doi: 10.1038/s41589-018-0013-8

Gruber, R., and Horovitz, A. (2016). Allosteric mechanisms in chaperonin machines. Chem. Rev. 116, 6588-6606. doi: 10.1021/acs.chemrev.5b0 0556

Grundtman, C., Kreutmayer, S. B., Almanzar, G., Wick, M. C., and Wick, G. (2011). Heat shock protein 60 and immune inflammatory responses in atherosclerosis. Arterioscler. Thromb. Vasc. Biol. 31, 960-968. doi: 10.1161/ATVBAHA.110.21 7877

Hayer-Hartl, M., Bracher, A., and Hartl, F. U. (2016). The GroEL-GroES chaperonin machine: a nano-cage for protein folding. Trends Biochem. Sci. 41, 62-76. doi: 10.1016/j.tibs.2015.07.009

Hemmingsen, S. M., Woolford, C., van der Vies, S. M., Tilly, K., Dennis, D. T., Georgopoulos, C. P., et al. (1988). Homologous plant and bacterial proteins chaperone oligomeric protein assembly. Nature 333, 330-334. doi: $10.1038 / 333330 \mathrm{a} 0$

Horwich, A. L., Farr, G. W., and Fenton, W. A. (2006). GroEL-GroESmediated protein folding. Chem. Rev. 106, 1917-1930. doi: 10.1021/cr04 $0435 \mathrm{v}$

Ishii, N., Taguchi, H., Sasabe, H., and Yoshida, M. (1995). Equatorial split of holo-chaperonin from Thermus thermophilus by ATP and K+. FEBS Lett. 362, 121-125. doi: 10.1016/0014-5793(95)00222-U 
Jia, H., Halilou, A. I., Hu, L., Cai, W., Liu, J., and Huang, B. (2011). Heat shock protein 10 (Hsp10) in immune-related diseases: one coin, two sides. Int. J. Biochem. Mol. Biol. 2, 47-57.

Juwono, J., and Martinus, R. D. (2016). Does Hsp60 Provide a Link between mitochondrial stress and inflammation in diabetes mellitus? J. Diabetes Res. 2016:8017571. doi: 10.1155/2016/8017571

Nielsen, K. L., and Cowan, N. J. (1998). A single ring is sufficient for productive chaperonin-mediated folding in vivo. Mol. Cell 2, 93-99. doi: 10.1016/S1097-2765(00)80117-3

Nielsen, K. L., McLennan, N., Masters, M., and Cowan, N. J. (1999). A single-ring mitochondrial chaperonin (Hsp60-Hsp10) can substitute for GroEL-GroES in vivo. J. Bacteriol. 181, 5871-5875.

Ritossa, F. A. (1962). A new puffing pattern induced by temperature shock and DNP in Drosophila. Experientia 188, 571-573. doi: 10.1007/BF02172188

Roy, H., Cannon, S., and Gilson, M. (1988). Assembly of Rubisco from native subunits. Biochim. Biophys. Acta 957, 323-334. doi: 10.1016/0167-4838(88)90221-X

Skjaerven, L., Cuellar, J., Martinez, A., and Valpuesta, J. M. (2015). Dynamics, flexibility, and allostery in molecular chaperonins. FEBS Lett. 589, 2522-2532. doi: 10.1016/j.febslet.2015.06.019
Taguchi, H. (2015). Reaction cycle of chaperonin GroEL and via symmetric "Football" intermediate. J. Mol. Biol. 427, 2912-2918. doi: 10.1016/j.jmb.2015.04.007

Thirumalai, D., and Lorimer, G. H. (2001). Chaperonin-mediated protein folding. Annu. Rev. Biophys. Biomol. Struct. 30, 245-269. doi: 10.1146/annurev.biophys.30.1.245

Yan, X., Shi, Q., Bracher, A., Milicic, G., Singh, A. K., Hartl, F. U., et al. (2018). GroEL ring separation and exchange in the chaperonin reaction. Cell 172, 605.e11-617.e11. doi: 10.1016/j.cell.2017.12.010

Conflict of Interest Statement: The authors declare that the research was conducted in the absence of any commercial or financial relationships that could be construed as a potential conflict of interest.

Copyright $\odot 2018$ Breiman and Azem. This is an open-access article distributed under the terms of the Creative Commons Attribution License (CC BY). The use, distribution or reproduction in other forums is permitted, provided the original author(s) and the copyright owner(s) are credited and that the original publication in this journal is cited, in accordance with accepted academic practice. No use, distribution or reproduction is permitted which does not comply with these terms. 